\title{
Preoperative Systemic Inflammation and Complications Affect Long-term Gallbladder Carcinoma Outcomes Following Surgery with Curative Intent
}

\author{
TOMOYUKI ABE ${ }^{1}$, HIRONOBU AMANO $^{1,2}$, KEIJI HANADA $^{3}$, SHUJI YONEHARA ${ }^{4}$, TSUYOSHI KOBAYASHI ${ }^{2}$, \\ TOSHIKATSU FUKUDA ${ }^{5}$, MASAHIRO NAKAHARA ${ }^{1}$, YOSHINORI KURODA ${ }^{1}$ and TOSHIO NORIYUKI ${ }^{1,2}$ \\ Departments of ${ }^{1}$ Surgery, ${ }^{3}$ Gastroenterology, and ${ }^{4}$ Pathology, \\ Onomichi General Hospital, Onomichi, Hiroshima, Japan; \\ ${ }^{2}$ Department of Gastroenterological and Transplant Surgery, Applied Life Sciences, \\ Institute of Biomedical and Health Sciences, Hiroshima University, Hiroshima, Japan; \\ ${ }^{5}$ Department of Surgery, Hiroshima General Hospital of West Japan Railway Company, Hiroshima, Japan
}

\begin{abstract}
Background/Aim: Gallbladder carcinoma (GBCA) has extremely poor outcomes. We aimed to investigate clinicopathological prognostic variables, including the modified Glasgow prognostic score (mGPS), for patients with resected GBCA. Patients and Methods: This retrospective study included 54 patients with GBCA resected between 1996 and 2014. Univariate and multivariate analyses were performed to identify prognostic factors associated with overall and recurrence-free survival. Results: Curative resection (RO) was achieved in 43 patients (79.6\%). The median patient age was 74 years (range $=25-99$ years), and the majority $(n=33,61.1 \%)$ were women. Incidental GBCA was detected in 18 patients (33.3\%). The overall and recurrence-free survival rates were $63.3 \%$ and $55.8 \%$ at 3 years and $58.4 \%$ and $51.3 \%$ at 5 years, respectively. In multivariate analysis, postoperative intra-abdominal complications ( $p=0.015)$, non-curative resection $(p=0.008)$, worse histological type $(p=0.003)$, and elevated $m G P S$ $(p=0.002)$ were independent predictors of worse overall survival. Surgical complications $(p=0.015)$, non-curative resection ( $p=0.005)$, worse histological type $(p=0.002)$, and elevated $m G P S(p=0.022)$ were also independent predictors of worse recurrence-free survival. Conclusion: Curative resection was important for long-term survival for GBCA. A high preoperative $m G P S$ and occurrence of surgical complications were independent prognostic indicators of poor survival in $G B C A$.
\end{abstract}

Correspondence to: Hironobu Amano, MD, Ph.D., 722-8508. Tel: +81 848228111, Fax: +81 848233214, e-mail: amanojack@star.odn.ne.jp

Key Words: Gallbladder carcinoma, postoperative complication, modified Glasgow prognostic score, survival.
Progress in anesthesiology, perioperative management, and radiological intervention has made it possible to treat patients with gallbladder carcinoma (GBCA). Nonetheless, the prognosis of GBCA remains unsatisfactory, with reported 5year survival rates below $20 \%(1,2)$. GBCA is a relatively rare disease compared to gastrointestinal carcinoma; however, its incidence has been increasing worldwide as the most common malignant biliary neoplasm and seventh-most common type of gastrointestinal cancer (3).

Lymph node (LN) metastasis, poor tumor differentiation, and non-curative resection have been reported as independent predictors of poor prognosis following surgical resection in patients with GBCA (4-8). Although negative effects of preoperative inflammation associated with GBCA have been encountered in clinical settings, there is strong evidence that systemic inflammation plays an important role in cancer progression $(2,9)$. Inflammation-associated cytokines promote tumor development; interleukin-6, interleukin-1 and epidermal growth factor receptor are well-known factors produced by tumors and immune cells in the tumor environment (10). Serum C-reactive protein (CRP) and albumin levels are influenced by these pro-inflammatory cytokines, leading to hypoalbuminemia and elevated $\operatorname{CRP}(11,12)$. Preoperative CRP concentration and hypoalbuminemia could be related to the dismal long-term outcomes after resection with curative intent in various cancer types (2, 13). Among several predictive prognostic scores, including the Glasgow prognostic score (GPS), neutrophil-to-lymphocyte ratio, and modified GPS (mGPS), the assessment of patient prognosis by mGPS was shown to be effective in several cancer types (14-17). However, the relationship between mGPS and GBCA patient prognosis has not been reported to our knowledge.

Postoperative intra-abdominal complications negatively impacted long-term outcomes in patients with colorectal, 
Table I. Univariate and multivariate analysis of prognostic factors for overall survival in patients with gallbladder carcinoma following curative resection $(n=54)$.

\begin{tabular}{|c|c|c|c|c|c|c|c|}
\hline \multirow[t]{2}{*}{ Variable } & \multirow[b]{2}{*}{$\mathrm{N}(\%)$} & \multirow[b]{2}{*}{ 3-Year survival } & \multicolumn{3}{|c|}{ Univariate analysis } & \multicolumn{2}{|c|}{ Multivariate analysis } \\
\hline & & & 5-Year survival & $p$-Value & HR & $95 \% \mathrm{CI}$ & $p$-Value \\
\hline \multicolumn{8}{|l|}{ Gender } \\
\hline Male & $21(38.9 \%)$ & $61.0 \%$ & $53.3 \%$ & 0.983 & & & \\
\hline Female & $33(61.1 \%)$ & $64.9 \%$ & $57.2 \%$ & & & & \\
\hline \multicolumn{8}{|l|}{ Median age } \\
\hline$<74$ Years & $26(48.1 \%)$ & $63.4 \%$ & $58.5 \%$ & 0.520 & & & \\
\hline$\geq 74$ Years & $28(51.9 \%)$ & $63.2 \%$ & $53.0 \%$ & & & & \\
\hline \multicolumn{8}{|l|}{ Concomitant ADM } \\
\hline No & $48(88.9 \%)$ & $65.1 \%$ & $56.4 \%$ & 0.791 & & & \\
\hline Yes & $6(11.1 \%)$ & $50.0 \%$ & $50.0 \%$ & & & & \\
\hline \multicolumn{8}{|c|}{ Concomitant GB stone } \\
\hline No & $38(70.4 \%)$ & $59.0 \%$ & $52.5 \%$ & 0.441 & & & \\
\hline Yes & $16(29.6 \%)$ & $73.9 \%$ & $64.6 \%$ & & & & \\
\hline \multicolumn{8}{|l|}{ Abdominal pain } \\
\hline None & $33(61.1 \%)$ & $72.4 \%$ & $68.8 \%$ & 0.045 & 1.210 & $0.421-3.477$ & 0.724 \\
\hline Present & $21(38.9 \%)$ & $47.1 \%$ & $29.4 \%$ & & & & \\
\hline \multicolumn{8}{|c|}{$\begin{array}{l}\text { Anomalous arrangement of } \\
\text { the pancreaticobiliary ducts }\end{array}$} \\
\hline No & $45(83.3 \%)$ & $55.4 \%$ & $48.9 \%$ & 0.113 & & & \\
\hline Yes & $9(16.7 \%)$ & $100 \%$ & $87.5 \%$ & & & & \\
\hline \multicolumn{8}{|c|}{ Incidental GB cancer } \\
\hline No & $36(66.7 \%)$ & $65.6 \%$ & $55.3 \%$ & 0.883 & & & \\
\hline Yes & $18(33.3 \%)$ & $57.4 \%$ & $57.4 \%$ & & & & \\
\hline \multicolumn{8}{|c|}{ Preoperative CA19-9 } \\
\hline$<35 \mathrm{U} / \mathrm{ml}$ & $33(63.5 \%)$ & $74.3 \%$ & $65.0 \%$ & 0.048 & 3.010 & $0.743-12.187$ & 0.123 \\
\hline$\geq 35 \mathrm{U} / \mathrm{ml}$ & $19(36.5 \%)$ & $45.9 \%$ & $40.2 \%$ & & & & \\
\hline \multicolumn{8}{|l|}{ Preoperative CEA } \\
\hline$<5 \mathrm{ng} / \mathrm{ml}$ & $44(84.6 \%)$ & $71.3 \%$ & $62.1 \%$ & 0.012 & 1.146 & $0.397-3.308$ & 0.801 \\
\hline$\geq 5 \mathrm{ng} / \mathrm{ml}$ & $8(15.4 \%)$ & $25.0 \%$ & $25.0 \%$ & & & & \\
\hline \multicolumn{8}{|c|}{ Bile duct reconstruction } \\
\hline Without & $33(61.1 \%)$ & $68.0 \%$ & $59.2 \%$ & 0.438 & & & \\
\hline With & $21(38.8 \%)$ & $56.4 \%$ & $50.8 \%$ & & & & \\
\hline \multicolumn{8}{|l|}{ Lymphadenectomy } \\
\hline No & $19(35.2 \%)$ & $62.3 \%$ & $62.3 \%$ & 0.696 & & & \\
\hline Yes & $35(64.8 \%)$ & $63.9 \%$ & $51.6 \%$ & & & & \\
\hline \multicolumn{8}{|c|}{ Median operation time } \\
\hline$<286 \min$ & $27(50.0 \%)$ & $72.0 \%$ & $54.8 \%$ & 0.618 & & & \\
\hline$\geq 286 \mathrm{~min}$ & $27(50.0 \%)$ & $55.3 \%$ & $55.3 \%$ & & & & \\
\hline Median bleeding v & & & & & & & \\
\hline$<255 \mathrm{ml}$ & $27(50.0 \%)$ & $76.0 \%$ & $64.1 \%$ & 0.152 & & & \\
\hline$\geq 255 \mathrm{ml}$ & $27(50.0 \%)$ & $51.5 \%$ & $42.9 \%$ & & & & \\
\hline Complications (Cla & & & & & & & \\
\hline None & $43(79.6 \%)$ & $70.9 \%$ & $61.7 \%$ & 0.015 & 4.777 & $1.352-16.880$ & 0.015 \\
\hline Present & $11(20.4 \%)$ & $32.7 \%$ & $32.7 \%$ & & & & \\
\hline Resection & & & & & & & \\
\hline R0 & $43(79.6 \%)$ & $71.5 \%$ & $65.6 \%$ & 0.003 & 5.462 & $1.571-18.990$ & 0.008 \\
\hline $\mathrm{R} 1,2$ & $11(20.4 \%)$ & $25.0 \%$ & $12.5 \%$ & & & & \\
\hline Histological type & & & & & & & \\
\hline Pap/well & $49(90.7 \%)$ & $67.8 \%$ & $62.1 \%$ & $<0.001$ & 8.491 & $2.103-34.279$ & 0.003 \\
\hline Mod/poor/other & $5(9.3 \%)$ & $20.0 \%$ & $0 \%$ & & & & \\
\hline Lymph duct invasio & & & & & & & \\
\hline None & $33(61.1 \%)$ & $71.8 \%$ & $71.8 \%$ & 0.022 & 1.600 & $0.431-5.938$ & 0.482 \\
\hline Present & $21(38.3 \%)$ & $50.0 \%$ & $26.8 \%$ & & & & \\
\hline Lymph node metas & & & & & & & \\
\hline None & $14(25.9 \%)$ & $68.9 \%$ & $65.6 \%$ & 0.026 & 1.119 & $0.194-6.448$ & 0.900 \\
\hline Present & $40(74.1 \%)$ & $46.4 \%$ & $24.8 \%$ & & & & \\
\hline
\end{tabular}


Table I. Continued

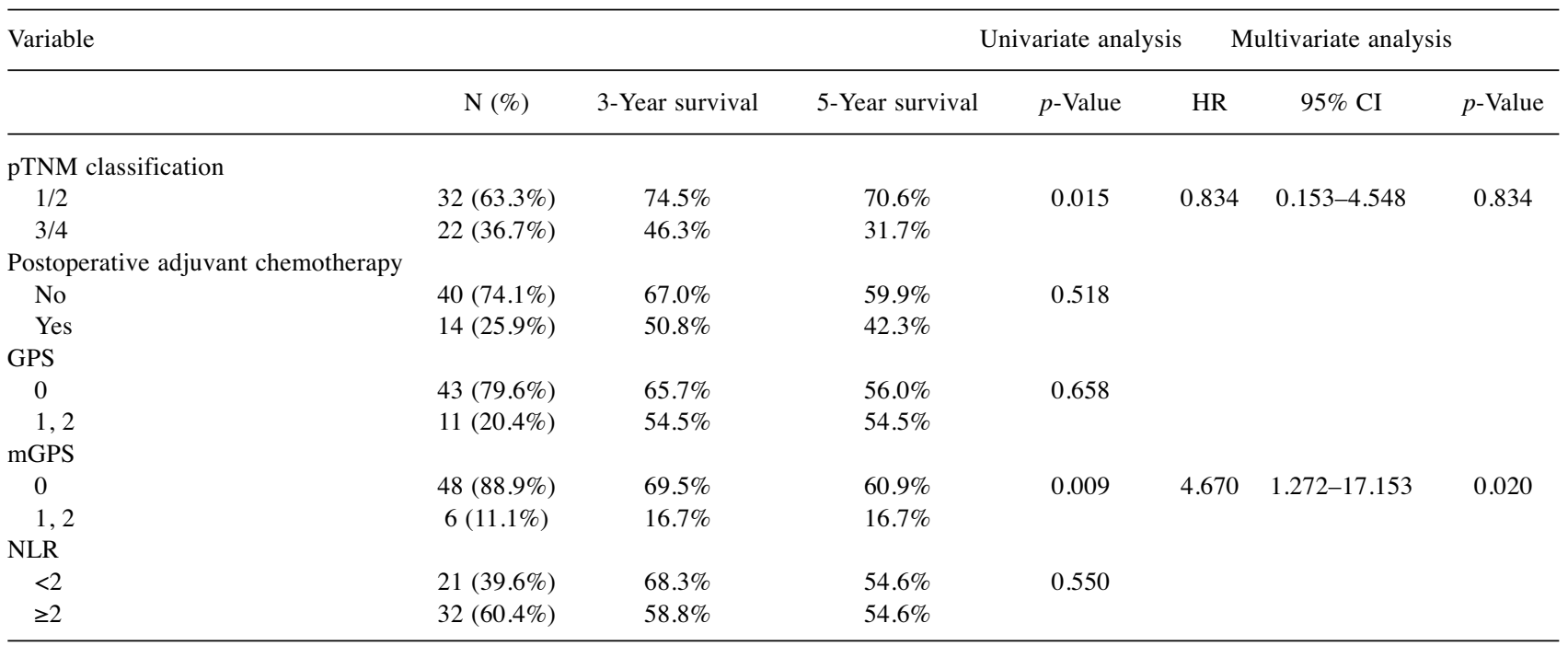

ADM, Adenomyomatosis; CA19-9, carbohydrate antigen 19-9; CEA, carcinoembryonic antigen; Pap/well: papillary/well-differentiated adenocarcinoma; Mod/poor/other: moderately/poorly differentiated adenocarcinoma/other types; CI, confidence interval; GB, gallbladder; GPS, Glasgow prognostic score; HR, hazard ratio; mGPS, modified GPS; NLR, neutrophil to lymphocyte ratio; pTNM, pathological tumor-nodemetastasis.

esophageal, and gastric cancer (18-21). In regard to GBCA, there have been no reports indicating whether postoperative abdominal complications have a negative impact on longterm outcomes. Concerns have been raised as to whether immune system suppression caused by preoperative systemic inflammation and surgical complications might promote cancer seeding.

Therefore, it is important to evaluate the prognostic power of mGPS and surgical complications in patients with GBCA who undergo curative resection, in order to select the patients who will gain the maximal benefit from surgical interventions. The objective of this study was to elicit potential predictors of long-term survival of patients with GBCA.

\section{Patients and Methods}

Patients. A retrospective study spanning an 18-year period from January 1996 to December 2014 was performed, and a total of 65 consecutive inpatients were identified. Eleven patients were excluded from this study: three who underwent palliative surgery and eight due to the loss of clinical data. Clinical data, tumor characteristics, and survival outcome were reviewed retrospectively. The study was approved by the local Institutional Review Board (no. 27-10) after informed consent was obtained from all patients.

Surgical procedure. Our strategy for curative resection included simple cholecystectomy for T1 GBCA and extended cholecystectomy with regional LN dissection, with or without wedge resection of the gallbladder bed for T2 GBCA. In the case of invasion of the cystic duct or the hepatoduodenal ligament, or on suspicion of metastatic hepatoduodenal LN, extrahepatic bile duct resection was performed. Liver segments IVa and V were indicated when cancer directly invaded the liver bed, and right hepatectomy when it had invaded the right Glisson's capsule. Regional LN dissection included the common hepatic artery (LN\#8), proper hepatic artery (\#LN12a), bile duct (\#LN12b), portal vein (\#LN12p), and retropancreatic LNs (LN\#13). If the tumor invasion was T2 or more after simple cholecystectomy, hepatic wedge resection with LN dissection was additionally performed. Tumor staging was performed according to the pathological tumor node metastasis (pTNM) classification, based on the International Union Against Cancer TNM classification (22).

Definitions of the modified GPS and other scores. The following possible prognostic factors were examined with respect to overall and recurrence-free survival: mGPS, age, sex, presence of adenomyomatosis and gallbladder stone, clinical symptoms, anomalous arrangement of the pancreaticobiliary ducts, tumor size, number of tumors, tumor differentiation, microvascular invasion, serum carbohydrate antigen 19-9 (CA19-9), serum carcinoembryonic antigen (CEA) level, bile duct reconstruction, lymphadenectomy, duration of surgery, estimated blood loss, complication, and success of resection. Prior to the operation, blood samples were collected, and routine laboratory analyses of CRP and albumin levels were performed. Values for mGPS were calculated as follows: patients with elevated CRP (defined as $>1.0 \mathrm{mg} / \mathrm{dl}$ ) received a score of 1 or 2 depending on the presence or absence of hypoalbuminemia $(<3.5 \mathrm{~g} / \mathrm{dl})$; patients without elevated CRP levels were assigned a score of 0 .

Morbidity and complications. Complications were defined according to the method described by Clavien et al. (23). In this study, 
Table II. Univariate and multivariate analysis of prognostic factors for recurrence-free survival in patients with gallbladder carcinoma following curative resection $(n=54)$.

\begin{tabular}{|c|c|c|c|c|c|c|c|}
\hline \multirow[t]{2}{*}{ Variable } & \multirow[b]{2}{*}{$\mathrm{N}(\%)$} & \multirow[b]{2}{*}{ 3-Year survival } & \multicolumn{3}{|c|}{ Univariate analysis } & \multicolumn{2}{|c|}{ Multivariate analysis } \\
\hline & & & 5-Year survival & $p$-Value & HR & $95 \% \mathrm{CI}$ & $p$-Value \\
\hline \multicolumn{8}{|l|}{ Gender } \\
\hline Male & $21(38.9 \%)$ & $61.2 \%$ & $54.4 \%$ & 0.651 & & & \\
\hline Female & $33(61.1 \%)$ & $56.7 \%$ & $49.6 \%$ & & & & \\
\hline \multicolumn{8}{|l|}{ Median age } \\
\hline$<74$ Years & $26(48.1 \%)$ & $60.9 \%$ & $56.2 \%$ & 0.403 & & & \\
\hline$\geq 74$ Years & $28(51.9 \%)$ & $56.0 \%$ & $46.2 \%$ & & & & \\
\hline \multicolumn{8}{|l|}{ Concomitant ADM } \\
\hline No & $48(88.9 \%)$ & $59.5 \%$ & $51.2 \%$ & 0.995 & & & \\
\hline Yes & $6(11.1 \%)$ & $50.0 \%$ & $50.0 \%$ & & & & \\
\hline \multicolumn{8}{|c|}{ Concomitant GB stone } \\
\hline No & $38(70.4 \%)$ & $54.6 \%$ & $48.2 \%$ & 0.441 & & & \\
\hline Yes & $16(29.6 \%)$ & $68.2 \%$ & $59.7 \%$ & & & & \\
\hline \multicolumn{8}{|l|}{ Abdominal pain } \\
\hline None & $33(61.1 \%)$ & $69.7 \%$ & $62.5 \%$ & 0.051 & & & \\
\hline Present & $21(38.9 \%)$ & $44.4 \%$ & $29.6 \%$ & & & & \\
\hline \multicolumn{8}{|c|}{$\begin{array}{l}\text { Anomalous arrangement of } \\
\text { the pancreaticobiliary ducts }\end{array}$} \\
\hline No & $45(83.3 \%)$ & $52.5 \%$ & $46.7 \%$ & 0.173 & & & \\
\hline Yes & $9(16.7 \%)$ & $87.5 \%$ & $75.0 \%$ & & & & \\
\hline \multicolumn{8}{|c|}{ Incidental GB cancer } \\
\hline No & $36(66.7 \%)$ & $60.7 \%$ & $50.6 \%$ & 0.980 & & & \\
\hline Yes & $18(33.3 \%)$ & $53.8 \%$ & $53.8 \%$ & & & & \\
\hline \multicolumn{8}{|c|}{ Preoperative CA19-9 } \\
\hline$<35 \mathrm{U} / \mathrm{ml}$ & $33(63.5 \%)$ & $69.4 \%$ & $56.9 \%$ & 0.158 & & & \\
\hline$\geq 35 \mathrm{U} / \mathrm{ml}$ & $19(36.5 \%)$ & $40.2 \%$ & $40.2 \%$ & & & & \\
\hline \multicolumn{8}{|l|}{ Preoperative CEA } \\
\hline$<5 \mathrm{ng} / \mathrm{ml}$ & $44(84.6 \%)$ & $65.1 \%$ & $56.5 \%$ & 0.041 & 3.394 & $0.991-11.616$ & 0.052 \\
\hline$\geq 5 \mathrm{ng} / \mathrm{ml}$ & $8(15.4 \%)$ & $25.0 \%$ & $25.0 \%$ & & & & \\
\hline \multicolumn{8}{|c|}{ Bile duct reconstruction } \\
\hline Without & $33(61.1 \%)$ & $59.7 \%$ & $55.7 \%$ & 0.541 & & & \\
\hline With & $21(38.8 \%)$ & $56.4 \%$ & $44.4 \%$ & & & & \\
\hline \multicolumn{8}{|l|}{ Lymphadenectomy } \\
\hline No & $19(35.2 \%)$ & $62.3 \%$ & $62.3 \%$ & 0.402 & & & \\
\hline Yes & $35(64.8 \%)$ & $56.3 \%$ & $44.7 \%$ & & & & \\
\hline \multicolumn{8}{|c|}{ Median operation time } \\
\hline$<286 \min$ & $27(50.0 \%)$ & $66.4 \%$ & $49.8 \%$ & 0.482 & & & \\
\hline$\geq 286 \mathrm{~min}$ & $27(50.0 \%)$ & $49.2 \%$ & $49.2 \%$ & & & & \\
\hline Median bleeding $\mathrm{v}$ & & & & & & & \\
\hline$<255 \mathrm{ml}$ & $27(50.0 \%)$ & $61.9 \%$ & $61.9 \%$ & 0.098 & & & \\
\hline$\geq 255 \mathrm{ml}$ & $27(50.0 \%)$ & $49.0 \%$ & $32.6 \%$ & & & & \\
\hline Complications $(\mathrm{Cla}$ & & & & & & & \\
\hline None & $43(79.6 \%)$ & $64.5 \%$ & $56.0 \%$ & 0.041 & 4.437 & $1.341-14.66$ & 0.015 \\
\hline Present & $11(20.4 \%)$ & $32.7 \%$ & $32.7 \%$ & & & & \\
\hline Resection & & & & & & & \\
\hline Ro & $43(79.6 \%)$ & $66.9 \%$ & $60.9 \%$ & 0.001 & 4.976 & $1.616-15.328$ & 0.005 \\
\hline $\mathrm{R} 1,2$ & $11(20.4 \%)$ & $11.4 \%$ & $11.4 \%$ & & & & \\
\hline Histological type & & & & & & & \\
\hline Pap/well & $49(90.7 \%)$ & $64.7 \%$ & $56.8 \%$ & 0.000 & 8.338 & $2.129-32.661$ & 0.002 \\
\hline Mod/poor/other & $5(9.3 \%)$ & $0 \%$ & $0 \%$ & & & & \\
\hline Lymph duct invasi & & & & & & & \\
\hline None & $33(61.1 \%)$ & $69.4 \%$ & $65.8 \%$ & 0.029 & 1.471 & $0.425-5.098$ & 0.543 \\
\hline Present & $21(38.3 \%)$ & $40.6 \%$ & $27.1 \%$ & & & & \\
\hline Lymph node metas & & & & & & & \\
\hline None & $14(25.9 \%)$ & $67.0 \%$ & $63.8 \%$ & 0.004 & 1.034 & $0.196-5.456$ & 0.969 \\
\hline Present & $40(74.1 \%)$ & $35.7 \%$ & $13.4 \%$ & & & & \\
\hline
\end{tabular}


Table II. Continued

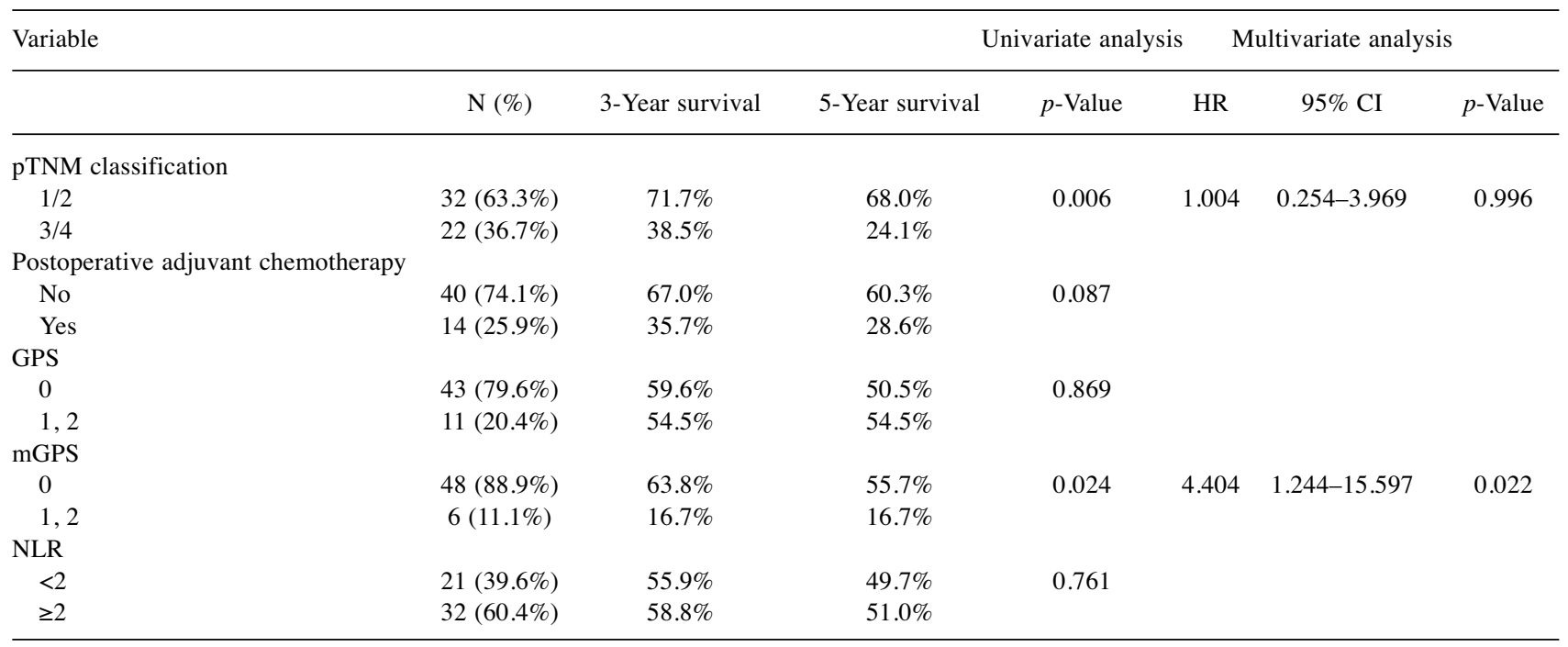

ADM, Adenomyomatosis; CA19-9, carbohydrate antigen 19-9; CEA, carcinoembryonic antigen; Pap/well: papillary/well-differentiated adenocarcinoma; Mod/poor/other: moderately/poorly differentiated adenocarcinoma/other types; CI, confidence interval; GB, gallbladder; GPS, Glasgow prognostic score; HR, hazard ratio; mGPS, modified GPS; NLR, neutrophil to lymphocyte ratio; pTNM, pathological tumor node metastasis.

postoperative complications were defined as those that were grade IIIA or greater, while postoperative mortality was defined as any death occurring within 30 days of surgery.

Statistical analyses. The Kaplan-Meier method was used to analyze overall and disease-free survival; the log-rank test was used to compare different groups. Multivariate analyses were used to assess factors influencing overall and disease-free survival using Cox's regression model. $p$-Values less than 0.05 were considered significant. Calculations were performed using SPSS software (version 22; IBM Corp., Armonk, NY, USA).

\section{Results}

Patient characteristics and surgical complications. Clinicopathological characteristics are summarized in Table I. Overall, 54 patients underwent resection with curative intent for GBCA at the Department of Surgery of Onomichi General Hospital during the study period. The median follow-up period after surgery was 3.0 years (range $=0.04-13.8$ years). The patient population included 21 men and 33 women, with a median age of 74 years (range $=25-99$ years). Operative procedures consisted of cholecystectomy in 23 cases $(42.6 \%)$, including lymphadenectomy in six and bile duct resection in three, and liver bed resection in $24(46.3 \%)$, including a secondary operation after diagnosis of GBCA by cholecystectomy with hepatic resection of segment $4 \mathrm{a}$ and segment 5 in four (7.4\%), extended right lobectomy in two (3.7\%), and central bisegmentectomy in one $(1.9 \%)$. Lymphadenectomy was performed in 35 patients $(64.8 \%)$, and bile duct reconstruction in $21(38.9 \%)$. mGPS was 0 in 48 patients $(88.9 \%)$.
In regard to surgical complications, postoperative complications (Clavien-Dindo $\geq$ IIIA) occurred in 11 patients $(20.4 \%)$, including anastomosis leakage in five $(9.3 \%)$, abdominal abscess in two (3.7\%), septic shock in three $(5.6 \%)$, and massive postoperative bleeding in one $(1.9 \%)$. The 1-, 3-, and 5-year survival rates of the 54 patients who underwent resection with curative intent were $83.1 \%, 63.3 \%$, and $55.8 \%$, respectively. Recurrence was observed in 15 patients $(27.8 \%)$ : four had hepatic recurrence, nine had LN recurrence, and two had peritoneal dissemination. The 1-, 3-, and 5-year recurrence-free survival rates of the whole group were $77.8 \%, 58.4 \%$, and $51.3 \%$, respectively.

Prognostic variables for overall and recurrence-free survival in univariate and multivariate analyses. In univariate analysis, abdominal pain, preoperative CA19-9 $\geq 35 \mathrm{U} / \mathrm{ml}$, preoperative $\mathrm{CEA} \geq 5 \mathrm{ng} / \mathrm{ml}$, complication, non-curative resection, poor histological type, pathological lymph duct invasion, LN metastasis, pTNM classification (22), and mGPS of 1 or 2 were significant risk factors for poor overall survival. In multivariate analysis, independent factors indicating poor prognosis included mGPS of 1 or $2(p=0.020)$, non-curative resection $(p=0.008)$, moderately/poorly differentiated/other histological type $(p=0.003)$, and occurrence of postoperative complication ( $p=0.015$; Table I). There was no significant difference between patients with mGPS of 0 and mGPS of 1 . Compared with patients with mGPS of 0 , patients with mGPS of 1 or 2 had a worse prognosis (Figure 1A). Classification 

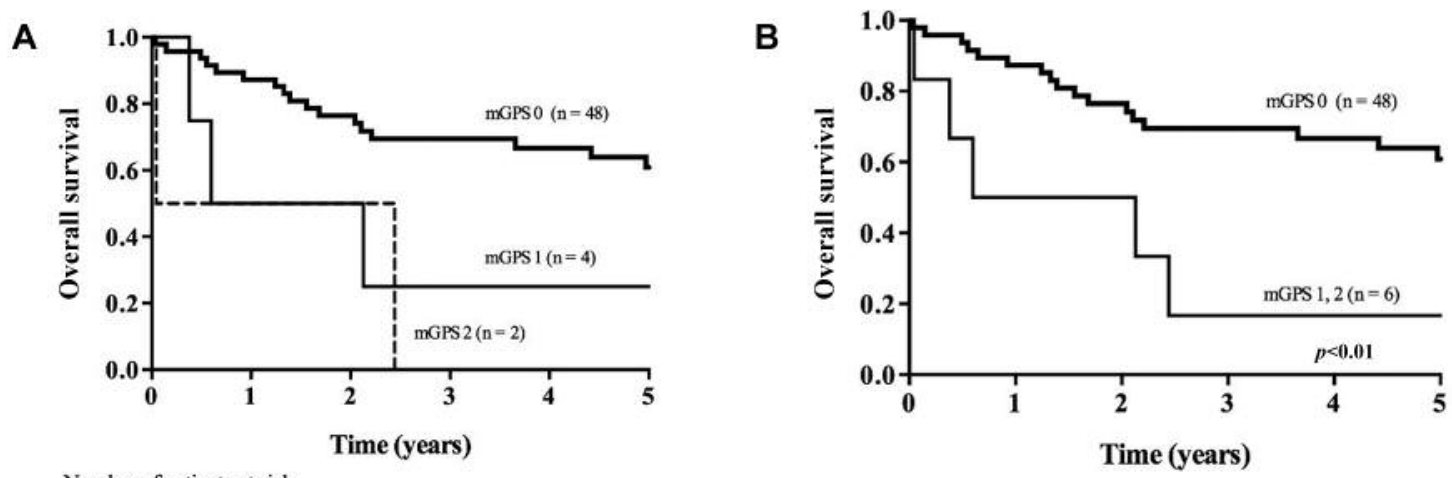

\begin{tabular}{lcccccc}
\multicolumn{7}{c}{ Number of patients at risk } \\
mGPS 0 & 48 & 41 & 33 & 25 & 24 & 20 \\
mGPS 1 & 4 & 2 & 2 & 1 & 1 & 1 \\
mGPS 2 & 2 & 1 & 1 & 0 & 0 & 0
\end{tabular}

\begin{tabular}{lcccccc}
\multicolumn{5}{c}{ Number of patients at risk } \\
mGPS 0 & 48 & 41 & 33 & 25 & 24 & 20 \\
mGPS 1,2 & 6 & 3 & 3 & 1 & 1 & 1
\end{tabular}

Figure 1. Overall survival according to modified Glasgow prognostic score (mGPS) status. A: Overall survival curves after surgery with curative intent according to mGPS. There was no significant difference between patients with $m G P S O$ and 1. B: The mGPS-negative group (mGPS 0 ) significantly differed from the mGPS-positive group ( $m G P S 1$ or 2$)(p<0.01)$.

A

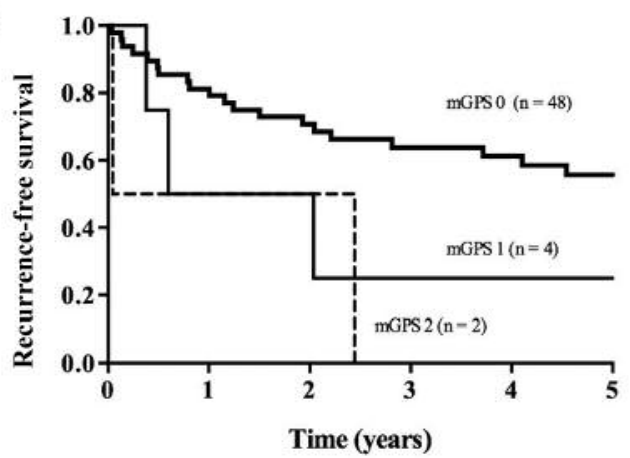

Number of patients at risk
B

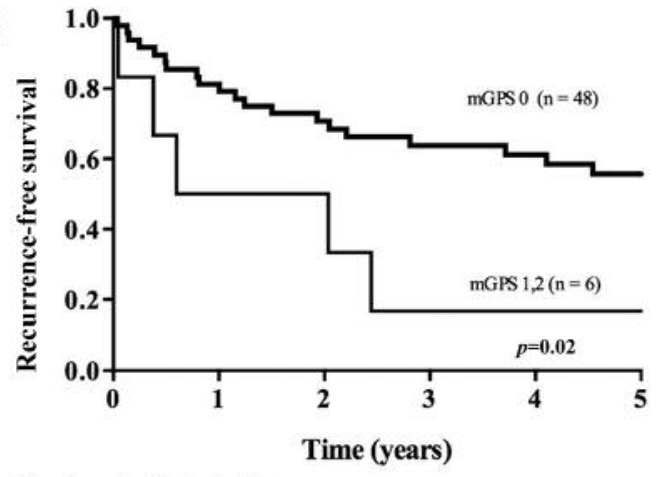

Number of patients at risk

$\begin{array}{llccccccccccc}\text { mGPS } 0 & 48 & 39 & 32 & 24 & 23 & 19 & \text { mGPS } 0 & 48 & 39 & 32 & 24 & 23 \\ \text { mGPS } 1 & 4 & 2 & 2 & 1 & 1 & 1 & \text { mGPS } 1,2 & 6 & 3 & 3 & 1 & 1 \\ \text { mGPS 2 } & 2 & 1 & 1 & 0 & 0 & 0 & & 1\end{array}$

Figure 2. Recurrence-free survival according to modified Glasgow prognostic score (mGPS) status. A: Recurrence-free survival curves showing the relationship between recurrence-free survival and mGPS in patients after surgery. Patients with $m G P S$ of 1 and 2 had a similar prognosis after surgery. B: The mGPS-negative ( $m G P S O)$ group significantly differed from the mGPS-positive group ( $m G P S 1$ or 2$)(p=0.02)$.

with an mGPS of 0 versus an mGPS of 1 or 2 had a strong impact on overall patient survival $(\mathrm{p}<0.01$; Figure $1 \mathrm{~B})$.

In univariate analysis, preoperative CEA $\geq 5 \mathrm{ng} / \mathrm{ml}$, complication, curative resection, poor histological type, pathological lymph duct invasion, LN metastasis, pTNM classification, and mGPS of 1 or 2 were significant risk factors for poor recurrence-free survival. In multivariate analysis, prognostic factors included mGPS of 1 or $2(p=0.022)$, curative resection $(p=0.005)$, histological type (moderate/poor/other types) ( $p=0.002)$, and occurrence of postoperative complication
( $p=0.015$; Table II). On three-group stratification, there were no significant differences between patients with mGPS of 0 and mGPS of 1 (Figure 2A). Classification with mGPS of 0 versus mGPS of 1 or 2 had a strong impact on recurrence-free survival $(p=0.020$; Figure $2 \mathrm{~B})$.

\section{Discussion}

Survival after surgical resection for patients with GBCA depends heavily on disease stage and whether curative 
resection is achieved. In this single-institution, retrospective analysis of patients with GBCA who underwent surgery with curative intent, we identified postoperative intra-abdominal complications, non-curative resection, poor histological type, and elevated mGPS score as independent predictors of worse overall survival. Postoperative complications, non-curative resection, poor histological type, and elevated mGPS score were independent predictors of worse recurrence-free survival.

Previous reports demonstrated that cancer-related inflammation has a negative impact on the prognosis of patients after surgery for $\operatorname{GBCA}(2,9)$. Consistent with those findings, our study showed that elevated mGPS was associated with worse long-term survival. Among several independent prognostic variables, mGPS can be obtained preoperatively and it is easy to identify patients with elevated mGPS scores. To the best of our knowledge, this study is the first to report the relationship between surgical outcomes of GBCA and mGPS.

We previously found that GPS positivity (GPS $>0$ ) has a negative impact on the prognosis of patients with hepatocellular carcinoma who underwent living-donor liver transplantation (24). In general, patients with hepatocellular carcinoma have severe liver dysfunction, with reduced liver production of albumin and CRP. In contrast, GBCA occurrence is not related to liver cirrhosis, and patients with GBCA have a comparatively normal liver.

An advantage of mGPS is that it can be used to predict outcomes preoperatively. The criteria for mGPS are strictly determined by serum CRP, not albumin. Several advocates of the mGPS point out that it has a superior predictive power compared to GPS in patients with hepatocellular carcinoma and colorectal carcinoma since serum albumin is influenced by several factors $(14,15)$.

The mechanism underlying the relationship between elevated mGPS and poor patient prognosis remains unclear. Several reports have suggested that postoperative infectious complications are highly associated with mGPS elevation due to deterioration of immune cell activity $(25,26)$. In our study, it is of interest that the postoperative infectious complication rate was similar across mGPS scores. However, the long-term prognosis was dismal in patients who had a postoperative complication, suggesting that the perioperative innate immune system could play an important role in predicting tumor recurrence. Tumor-derived, inflammation-related cytokines have a negative impact on tumor recurrence and survival. Combined with pathological findings, mGPS could be helpful to select appropriate patients who are at high risk of tumor recurrence, even though there is no established adjuvant chemotherapy for GBCA after surgery (27).

Surgical complication was also an indicator for poor prognosis. Anastomotic leakage was the main surgical complication, which can allow seeding of viable cancer cells $(28,29)$. Another possibility is that complications influence the suppression of immune cell activity, leading to enhanced metastatic growth. Surgical stress and tissue damage by themselves can compromise natural killer cells, which possess high antitumor activity (30). Thus, an elevated mGPS score and postoperative intra-abdominal complications are both strongly related to host immune activity. To prevent surgical complications, a multimodal approach is necessary to increase the likelihood of early recovery from surgery.

This study has several limitations. This was a retrospective, single-center study. Secondly, only six patients had an mGPS greater than 0 ; the distribution of patient preoperative parameters could make it difficult to elucidate the relationship between preoperative inflammatory state and mGPS. Future prospective cohort studies including multiple institutions are necessary to clarify these potential crossinteraction mechanisms.

\section{Conclusion}

The presence of preoperative systemic inflammation has a strong impact on long-term prognosis in patients with GBCA. The preoperative mGPS evaluation is a simple and effective means to predict long-term outcomes in patients with GBCA following surgery with curative intent. Postoperative intra-abdominal complications affect long-term prognosis, even after curative surgery. Surgeons should take meticulous care to prevent and reduce complications.

\section{Conflicts of Interest}

There is no conflict of interest to disclose.

\section{Informed Consent}

Informed consent was obtained from all individual participants included in the study.

\section{Acknowledgements}

The Authors would like to thank the Center of Life Science at Hiroshima University for the use of their facilities, and Minoru Hattori for assisting in the statistical analysis.

\section{References}

1 Zhang Y, Huang Y and Qin M: Tumour-infiltrating FoxP3+ and IL-17-producing T-cells affect the progression and prognosis of gallbladder carcinoma after surgery. Scand J Immunol 78: 516$522,2013$.

2 Han HS, Cho JY, Yoon YS, Ahn KS and Kim H: Preoperative inflammation is a prognostic factor for gallbladder carcinoma. Br J Surg 98: 111-116, 2011.

3 Donohue JH, Stewart AK and Menck HR: The National Cancer Data Base report on carcinoma of the gallbladder, 1989-1995. Cancer 83: 2618-2628, 1998 
4 Kondo S, Nimura Y, Hayakawa N, Kamiya J, Nagino M and Uesaka K: Extensive surgery for carcinoma of the gallbladder. Br J Surg 89: 179-184, 2002.

5 Horiguchi A, Miyakawa S, Ishihara S, Miyazaki M, Ohtsuka M, Shimizu H, Sano K, Miura F, Ohta T, Kayahara M, Nagino M, Igami T, Hirano S, Yamaue H, Tani M, Yamamoto M, Ota T, Shimada M, Morine Y, Kinoshita H, Yasunaga M and Takada T: Gallbladder bed resection or hepatectomy of segments $4 \mathrm{a}$ and 5 for pT2 gallbladder carcinoma: analysis of Japanese registration cases by the study group for biliary surgery of the Japanese Society of Hepato-Biliary-Pancreatic Surgery. J Hepatobiliary Pancreat Sci 20: 518-524, 2013.

6 Schauer RJ, Meyer G, Baretton G, Baretton G, Schildberg FW and Rau HG: Prognostic factors and long-term results after surgery for gallbladder carcinoma: a retrospective study of 127 patients. Langenbecks Arch Surg 386: 110-117, 2001.

7 Miura F, Asano T, Amano H, Toyota N, Wada K, Kato K, Takada T, Takami H, Ohira G and Matsubara $\mathrm{H}$ : New prognostic factor influencing long-term survival of patients with advanced gallbladder carcinoma. Surgery 148: 271-277, 2010.

8 Pilgrim CH, Groeschl RT, Turaga KK and Gamblin TC: Key factors influencing prognosis in relation to gallbladder cancer. Dig Dis Sci 58: 2455-2462, 2013.

9 Shiba H, Misawa T, Fujiwara Y, Futagawa Y, Furukawa K, Haruki K, Iwase R, Iida T and Yanaga K: Glasgow prognostic score predicts outcome after surgical resection of gallbladder cancer. World J Surg 39: 753-758, 2015.

10 Diakos CI, Charles KA, McMillan DC and Clarke SJ: Cancerrelated inflammation and treatment effectiveness. Lancet Oncol 15: e493-503, 2014.

11 Proctor MJ, Horgan PG, Talwar D, Fletcher CD, Morrison DS and McMillan DC: Optimization of the systemic inflammationbased Glasgow prognostic score: a Glasgow Inflammation Outcome Study. Cancer 119: 2325-2332, 2013.

12 Mantovani A, Allavena P, Sica A and Balkwill F: Cancer-related inflammation. Nature 454: 436-444, 2008.

13 Maccio A, Madeddu C, Gramignano G, Mulas C, Tanca L, Cherchi MC, Floris C, Omoto I, Barracca A and Ganz T: The role of inflammation, iron, and nutritional status in cancerrelated anemia: results of a large, prospective, observational study. Haematologica 100: 124-132, 2015.

14 Park JH, Watt DG, Roxburgh CS, Horgan PG and McMillan DC: Colorectal cancer, systemic inflammation, and outcome: staging the tumor and staging the host. Ann Surg 263(2): 326$336,2015$.

15 Nakagawa K, Tanaka K, Nojiri K, Kumamoto T, Takeda K, Ueda $\mathrm{M}$ and Endo I: The modified Glasgow prognostic score as a predictor of survival after hepatectomy for colorectal liver metastases. Ann Surg Oncol 21: 1711-1718, 2014.

16 Adachi T, Hinoi T, Hattori M, Egi H, Shimomura M, Saito Y, Sawada H, Miguchi M, Niitsu H, Mukai S, Yano T and Ohdan $\mathrm{H}$ : The modified Glasgow prognostic score for early mortality in patients with synchronous peritoneal carcinomatosis from colorectal cancer. Surg Today 45: 1396-1403, 2015.

17 Shafique K, Proctor MJ, McMillan DC, Leung H, Smith K, Sloan B and Morrison DS: The modified Glasgow prognostic score in prostate cancer: results from a retrospective clinical series of 744 patients. BMC Cancer 13: 292, 2013.

18 Tokunaga M, Tanizawa Y, Bando E, Kawamura T and Terashima M: Poor survival rate in patients with postoperative intra- abdominal infectious complications following curative gastrectomy for gastric cancer. Ann Surg Oncol 20: 1575-1583, 2013.

19 Hirai T, Yamashita Y, Mukaida H, Kuwahara M, Inoue H and Toge T: Poor prognosis in esophageal cancer patients with postoperative complications. Surg Today 28: 576-579, 1998.

20 Lerut T, Moons J, Coosemans W, Van Raemdonck D, De Leyn P, Decaluwé H, Decker $G$ and Nafteux P: Postoperative complications after transthoracic esophagectomy for cancer of the esophagus and gastroesophageal junction are correlated with early cancer recurrence: role of systematic grading of complications using the modified Clavien classification. Ann Surg 250: 798-807, 2009.

21 Saito T, Kurokawa Y, Miyazaki Y, Makino T, Takahashi T, Yamasaki M, Nakajima K, Takiguchi S, Mori M and Doki Y: Which is a more reliable indicator of survival after gastric cancer surgery: postoperative complication occurrence or C-reactive protein elevation? J SurgOncol 112: 894-899, 2015.

22. International Union Against Cancer (UICC): TNM Classification of Malignant Tumors, Seventh Edition. Sobin LH, Gospodarowicz MK and Wittekind C (eds.) New York: WileyBlackwell, 2010.

23 Clavien PA, Barkun J, de Oliveira ML, Vauthey JN, Dindo D, Schulick RD, de Santibañes E, Pekolj J, Slankamenac K, Bassi C, Graf R, Vonlanthen R, Padbury R, Cameron JL and Makuuchi M: The Clavien-Dindo classification of surgical complications: five-year experience. Ann Surg 250: 187-196, 2009.

24 Abe T, Tashiro H, Hattori M, Kuroda S, Tahara H, Ohira M, Kobayashi T, Ide K, Ishiyama K and Ohdan H: Prediction of longterm survival by using the Glasgow Prognostic Score in patients with hepatocellular carcinoma after liver transplantation. Hepatol Res doi: 10.1111/hepr.12597, 2015 [Epub ahead of print]

25 Moyes LH, Leitch EF, McKee RF, Anderson JH, Horgan PG and McMillan DC: Preoperative systemic inflammation predicts postoperative infectious complications in patients undergoing curative resection for colorectal cancer. Br J Cancer 100: 1236-1239, 2009.

26 Neal CP, Mann CD, Garcea G, Briggs CD, Dennison AR and Berry DP: Preoperative systemic inflammation and infectious complications after resection of colorectal liver metastases. Arch Surg 146: 471-478, 2011.

27 Horgan AM, Amir E, Walter T and Knox JJ: Adjuvant therapy in the treatment of biliary tract cancer: a systematic review and meta-analysis. J Clin Oncol 30: 1934-1940, 2012.

28 Bell SW, Walker KG, Rickard MJ, Sinclair G, Dent OF, Chapuis $\mathrm{PH}$ and Bokey EL: Anastomotic leakage after curative anterior resection results in a higher prevalence of local recurrence. Br J Surg 90: 1261-1266, 2003.

29 Walker KG, Bell SW, Rickard MJ, Mehanna D, Dent OF, Chapuis PH and Bokey EL: Anastomotic leakage is predictive of diminished survival after potentially curative resection for colorectal cancer. Ann Surg 240: 255-259, 2004.

30 Seth R, Tai LH, Falls T, de Souza CT, Bell JC, Carrier M, Atkins H, Boushey R and Auer RA: Surgical stress promotes the development of cancer metastases by a coagulation-dependent mechanism involving natural killer cells in a murine model. Ann Surg 258: 158-168, 2013. 